\title{
1. Towards a history of Indigenous statistics in Australia
}

\section{Tim Rowse}

In 2003, the Productivity Commission report Overcoming Indigenous Disadvantage: Key Indicators 2003 demonstrated that Australia now has an extensive (though not time-deep) statistical archive through which we can compare Indigenous and non-Indigenous people. The report points to twelve 'headline indicators', and seven 'strategic areas for action', and it operationalises the 'strategic areas for action' in terms of thirty variables on which Indigenous and non-Indigenous can be compared. ${ }^{l}$

It has not always been possible to make such a wide battery of Indigenous/non-Indigenous comparisons (nor Indigenous/Australia comparisons). In this paper I will trace the steps that Australian governments have taken to recognise an entity that we call the 'Indigenous population' and to state its characteristics in comparative, quantitative terms.

My story is a frankly teleological one, in two senses. First, in looking at the steps taken I will pay particular attention to the steps that led towards what we have now. Second, I will nominate a turning point or watershed: the period 1966-76. In this moment, Australian governments ceased to manage the statistical archive in one way and began to manage it in a new way.

\section{The watershed years}

What happened between 1966 and 1976? The 1966 Census was the first Australian census in which the Statistician was prepared to claim 'virtually complete' enumeration of the Aboriginal population; ${ }^{2}$ as I will show below, the first comparisons of 'Aboriginal' with Australia, in respect of education and occupation, were enabled by the 1966 Census. However, 1966 was also the last Australian census to make the distinction between 'full blood' Aborigines and Aborigines of mixed descent. So 1966 was not the beginning of comparisons over time.

At first sight, we could understand the repeal, by referendum, of s.127 of the Australian Constitution as a step towards the reformed statistical archive that we now use. However, the referendum was not clearly such a progressive step,

1 I will use 'Indigenous' to refer to the combined figures for those of Aboriginal and/or Torres Strait Islander descent. For much of the period discussed in this chapter, the term 'Aboriginal' was used loosely to refer to those whom I refer to as 'Indigenous Australians'.

2 Borrie (1975: 468) judged the 1954 Census to be the first for which reasonable estimates of the total Aboriginal plus Islander population are available'. 
for two reasons. One is that, notwithstanding the words of s.127 ('in reckoning the numbers of the people of the Commonwealth, or of a State or other part of the Commonwealth, aboriginal natives shall not be counted'), all governments had long been collecting data on their Indigenous populations, as they conceived them. The second is that it was open to statistical authorities to interpret the repeal of s.127 as mandating the merging of the enumerated Aborigine with the total population. That is, the repeal of s.127 could be interpreted as a mandate to include, without distinguishing, Indigenous Australians. The argument to continue to distinguish Indigenous Australians, and to distinguish them in new ways, had to be made independently of, and even in the face of, the inclusive rhetoric of the 1967 referendum campaign.

In 1971, in a reform that was not evidently related to the repeal of s.127, the census introduced a new classification question that gave respondents the opportunity to identify themselves and their household members as 'Aboriginal' or as 'Torres Strait Islander'. In 1976 we had the second census using this revised question, so 1976 marks the beginning of the possibility of systematic comparison over time of Indigenous with 'all Australia', and Aboriginal with Torres Strait Islander.

I should emphasise the word 'beginning', for in 1976 there was still much to be done to reform those parts of the statistical archive that are supplied by organisations, such as hospitals, that service Indigenous Australians. Borrie complained in 1975 that it was still:

...extraordinarily difficult to persuade all the relevant authorities that Aborigines should be distinguished so that separate statistics can be maintained. Nor, as yet, is there any agreement on how the Aboriginal population is to be defined in the collection of statistics for series other than the census... [S]ome officials have argued that it would be offensive or discriminatory to ask people if they were Aborigines, or even to ask their race (Borrie 1975: 460-1). ${ }^{3}$

Notwithstanding Borrie's sense of the difficulties of further reform in Australia's Indigenous statistics, I think that we can see the years 1966 to 1976 as a turning point. The old way that prevailed from the late nineteenth century to $1966 \mathrm{had}$ used the discredited terms of racial science. Under this old way it had been difficult, if not impossible, to compare the Indigenous population with the non-Indigenous population (or with 'all Australians', which is much the same

\footnotetext{
3 As well, Borrie argued in 1975 that 'substantial changes in racial identification... are occurring'. He expected that 'the group of people identifying as Aborigines and Islanders will become relatively stable, so statistics relating to this group should become increasingly useful as time goes by' (Borrie 1975: 473). In fact, demographers have since noticed that identity change is a persistent dynamic, a source of growth in the Indigenous population. This does not seem to have diminished the utility of the census.
} 
thing). The new era has two features: ethnic identities (Aboriginal and Torres Strait Islander) have replaced racial distinctions; and there are now more socioeconomic and biomedical variables for making distinctions within the Indigenous population. These two features of the reformed statistical archive combine to make it possible to compare, across many variables, certain policy-relevant trends in the Indigenous and non-Indigenous populations. Those comparisons have become the basis of an idea of social justice that is new, or newly prominent, in Australian public life: 'practical reconciliation'.

\section{Statistics for protection and assimilation}

I do not have the space to review, jurisdiction by jurisdiction, the structures of colonial, State and Territory statistics on Aborigines and Torres Strait Islanders up to 1966. However, in a sense I do not need to, because the various jurisdictions worked to a common model, that I will call here the protection/assimilation model. I derive this name from the commonly acknowledged periodisation of Australian Indigenous public policy. The era of 'protection' was instituted by a wave of colonial, State and Commonwealth law-making that lasted from the 1880s to the end of the First World War. The era of 'assimilation' lasted from the late 1930s until the early 1970s, as each State or Territory amended and then repealed these statutes and strove to bring Indigenous Australians within the same legislative and administrative frameworks as all other Australians, invoking the ideal of an 'Australian way of life' to which all were tending. I will argue that as the sequence of post-World War Two legislative reforms approached its end in the 1960s, many officials and policy intellectuals pointed to the inadequacies of the statistical archive in its protection/assimilation form.

What were the elements of the protection/assimilation statistical archive? By the third quarter of the nineteenth century, most Australian jurisdictions were keeping some record of what they thought to be the absolute size and the sex composition of the Aboriginal population. The various jurisdictions began to record the ages of Aborigines in different years (Victoria from 1871, New South Wales and Western Australia from 1891, Queensland from 1901, and South Australia, Tasmania and the Northern Territory from 1911). ${ }^{4}$ From 1860 to 1905 , as each colony began to form a specialised administration and statutory regime through which to govern their Indigenous populations, they recorded two other features of the populations: their genetic character (differentiating 'full blood' from 'others') and their relationship to administrative control. There were two variables within what I am calling administrative control, and each jurisdiction made use of at least one of them. The Indigenous population could be acknowledged as subject to enumeration or as living beyond enumeration, a distinction sometimes conveyed by the distinction between 'settled districts'

4 I infer these starting dates from Smith's figure 8.4.1 (Smith 1980: 219). 
and regions that were beyond settlement and enumeration. The other 'administrative control' variable has to do with some kind of institutional authority. Thus, some Indigenous people were classified according to whether or not they were 'in employ', or 'under the Act' or living within reserves and government institutions.

When the Commonwealth government began to standardise the Indigenous statistical archive in the 1911 Census, it adopted the Western Australian 1901 Census's version of this classifying practice. That is:

- Aborigines were enumerated if they were accessible to ordinary enumeration procedures

- all those not enumerated were assumed to be 'full-bloods' and their number was estimated

- the general census population included 'half-castes' (but not 'full-bloods')

- the Commonwealth published separate figures on 'full-bloods' and on 'half-castes' (Smith 1980: 27).

When the Commonwealth collaborated with the States in every June from 1924 to 1941 to make an annual count, they were interested in the size, the sex composition, the age composition, the race composition and the relationship to governing authority of their Indigenous populations. This protection/assimilation model of the Indigenous population lasted about eighty years, continuing until two-thirds of the twentieth century had elapsed.

\section{The crisis of the protection/assimilation model}

What happened in the 1960s to upset this way of constructing a statistical archive? This is going to be a research question for me and for Len Smith over the next few years, so my answer today is rather limited.

According to Borrie (1975: 455-6), Australia's statisticians had long defended their very limited practice of Indigenous enumeration by pointing to two constraints. One was practical (the difficulties of enumerating 'tribal people'), and the other legal (their interpretation of s.127 of the Constitution). By 1967 both of these obstacles had been overcome. However, Borrie also found among government officials the view that it was difficult to define who is an Aborigine and also 'a vaguely formulated, but nevertheless strongly held view that separate statistics are in some way discriminatory, even if collected in order to make special provision for Aborigines' (Borrie 1975: 456).

The word 'discrimination' is our clue to the crisis in the Indigenous statistical archive. Liberal opinion favouring 'assimilation' was obliged, by the mid-1960s, to consider whether there was a positive sense of 'discrimination'. That is, if Aboriginal people were not doing well and if the state had an obligation to help them do well, might it not be necessary for the state to discriminate in their 
favour in certain ways? And was it not necessary to 'discriminate' (in the sense of distinguish) Aboriginal from non-Aboriginal in order to know how badly or how well Aborigines were doing, so that 'positive discrimination' could be soundly based? Some historians now interpret the 1967 referendum as an expression of a widespread (though not universal) conviction that it was time for public policy to discriminate in Aborigines' favour, at least until they had 'caught up' with the rest of Australia in certain respects (Taffe 2005).

The idea that Australia was failing in its duty to improve Aborigines' conditions of life was given powerful intellectual expression in the Social Science Research Council of Australia's multi-author project 'Aborigines in Australian Society'. The Rowley Project (as I like to call it, after its Director, Professor C.D. Rowley) produced 14 books between 1970 and 1980. It was a common complaint of the Rowley Project authors that social scientists had insufficient data on Indigenous Australians. Finding the census inadequate, Leonard Broom and Frank Jones remarked of Aboriginal affairs administration that 'the management of a rubbish tip is more carefully monitored' (Broom \& Jones 1973: 75). For example, they reported that there were no reliable statistics on Aboriginal mortality other than about 15 years of records for the Northern Territory (Broom \& Jones 1973: 63). For W. E. H. Stanner, 'the very absence of more precise information is itself the best evidence of past indifference' (Stanner 1970: vi-ix). Peter Moodie, in his study of Aboriginal health, pointed to official 'caginess' about quantifying 'the Aboriginal problem' (Moodie 1973: 275). However, he feared also that Aborigines themselves might resist distinguishing 'any self-identifying Aborigines' in databases (Moodie 1973: 274). He urged Aborigines to consider that by allowing their 'statistical visibility', Maoris and American Indians had improved their mortality (Moodie 1973: 122).

The argument for Aborigines' 'statistical visibility', carried strongly by social scientists, was heard by the Whitlam government (and possibly it was influential under the Coalition governments in the formulation of the race question in the 1971 Census). In 1975, Borrie welcomed the terms of reference of the Whitlam government's National Population Inquiry 'that it should include the Aboriginal population not only in the total situation, but also as a separate sub-study'. He commented that, 'There is no doubt that a separate study is needed. In every conceivable comparison, the Aborigines and Islanders, whom it is proposed in general to treat in one group, stand in stark contrast to the general Australian society, and also to other "ethnic" groups' (Borrie 1975: 455).

However, social scientists in the Rowley project had had to work with what they could find in the unreformed statistical archive. To illustrate the variety of their responses to its limitations, I will briefly outline what Rowley, Broom and Jones did. 
Rowley showed one way that the racial distinctions in the extant statistical archive could be meaningful. He argued that there were two kinds of situation facing Aborigines: 'colonial' Australia and 'settled' Australia. Though his description of the difference between the two situations drew attention to differences in their characteristic histories of colonisation and in their resulting social institutions (Rowley 1970c: 2), he suggested a numeric index for deciding whether a region was 'colonial' or 'settled': the relative proportions of the full-blood and the mixed descent components in the Aboriginal population in each Statistical Division, according to the 1961 Census. We retain much of Rowley's geographic binary when nowadays we compare 'remote' and 'non-remote' Indigenous statistics using the 2002 NATSISS.

In the Destruction of Aboriginal Society, Rowley (1970a) used 1961 Census and 1964 State/Territory estimates to show, State by State (but not Tasmania) the varying density (gross number per shire) of the Indigenous population. Differentiating full-blood from half-caste, he calculated their proportions in States and in capital cities, and he compared their distribution between urban and rural in each State/Territory. Distinguishing 'full-blood' from 'mixed-blood', he compared the age structures of each jurisdiction. He projected full-blood and mixed-blood population growth for 1961-81. The analytical value of distinguishing 'half-caste' from 'full-blood' is not clear, as Rowley preferred to account for Aborigines' behaviour by reference to their socialisation, not by reference to their genetic characteristics. However, the statistical archive that he had to work with was shaped by the genetic terms of an earlier era, so we get table after table distinguishing 'full-blood' from 'half-caste'.

Where he could do without the inherited statistical archive, Rowley did not distinguish half-castes and full-bloods. Researching Outcasts in White Australia (Rowley 1970b) he conducted two regional surveys (NSW outside Sydney, and Eyre Peninsula) with Aboriginal respondents. Without any reference to genetic characteristics, he presented data on Aborigines' housing quality, school attainments, books in dwellings, institutional background, water supply, bathing facilities, sanitation, garbage disposal, household composition, occupation, previous and current employment, skills and experience, post-primary education and training, and average weekly wage. He looked at their receipt of social security benefits, their ownership of property, their use of hire purchase, and their use of insurance policies. On some of these variables, he tabulated men and women separately.

In a few of his arguments, Rowley compared Aborigines with non-Aborigines. In Destruction of Aboriginal Society, he did so only to the extent of comparing the age structures of the full-blood, mixed-blood, and 'all Australians' groups. In Outcasts in White Australia, Rowley analysed his data on 'weekly income from all sources' and on 'membership of clubs and organisations' by comparing 
Aborigines in rural NSW and Eyre Peninsula with non-Aborigines in the same regions. He obtained from the Commonwealth Bureau of Census and Statistics and from the Western Australian Government statistics on types of offence, leading to conviction or committal, for 1962-64. From NSW, Victoria and South Australia he obtained comparative data on types of offences for which Aborigines and non-Aborigines were arrested and charged in the second six months of 1965.

In A Blanket a Year (1973) Leonard Broom and Frank Jones had a rather different agenda, enabled partly because, writing later than Rowley, they had the fruits of the first reforms of the statistical archive. The 1966 Census, as well as being the first to claim complete enumeration, was the first to release data on Aborigines in the same terms as the data for other Australians. Broom and Jones were able to compare the educational and workforce status of Aborigines with non-Aborigines. However, we should note exactly what they meant by 'Aborigines', for in their efforts to compare Aborigines and non-Aborigines, Broom and Jones were still burdened by the racial classifications of the unreformed archive. Their data on 'Aborigines' included only those classified in the 1966 Census as having ' 50 per cent or more Aboriginal ancestry'. They wrote that 'comparable data for approximately 16000 to 17000 identifiable Aborigines of less than 50 per cent have not been released, and they therefore cannot be dealt with here' (Broom \& Jones 1973: 13). Broom and Jones were concerned that by delimiting the Aboriginal population to those with 50 per cent or more Aboriginal descent, their comparison 'may exaggerate the...dissimilarity between Aborigines as a whole and the rest of the population' (Broom \& Jones 1973: 24). In a section headed 'selection as a factor in Aboriginal health statistics', Moodie also worried about the 'bias' in the construction of Aboriginal health data, though the distortion that he pointed to was in terms of the institutional rather than the genetic ordering of the 'Aboriginal population' (Moodie 1973: 23). That is, data on Aboriginal health tended to be about 'the more closely supervised government settlements, mission settlements, and the larger cattle stations'. These people were both 'in a dependent situation' and enjoyed 'better access to medical and health services' (for which they did not have to pay) than the more independent, but less well serviced 'relatively large fringe-dwelling and metropolitan groups' (Moodie 1973: 23).

Although they issued such caveats about the bias in their 'Aboriginal' categories, Broom and Jones and Moodie can be said to have initiated the research program that is now familiar to us as the comparative study of Indigenous and non-Indigenous labour market status, human capital acquisition and health status. These are among the pioneer works of our contemporary paradigm.

Broom and Jones were pioneers in another way. They constructed a 'total' Aboriginal population when they sought to project the growth in Aboriginal numbers. In this endeavour, they benefited from the Commonwealth 
Government's interpretation of its responsibilities after the repeal of s.127 in the May 1967 referendum. The referendum of 1967 led to the undifferentiated inclusion of Aborigines in birth, marriage and death registrations, making it possible for Broom and Jones to estimate plausibly Aboriginal fertility and infant mortality in the only jurisdiction where Aborigines were a large minority - the Northern Territory. By using these registration data and the 1961 and 1966 Census data, in two papers (Jones 1970, 1972) and in chapter four of his book with Broom, Jones gave an account of the distribution, fertility and mortality of the entire Aboriginal population - combining the 'dark' and the 'light' segments.

\section{Some features in the new archive}

Let me conclude by pointing to some features of the Indigenous statistical archive in its reformed, contemporary condition.

First, there has been a sustained agenda of reform. This agenda has been driven by a strong conviction that social justice demands Indigenous/non-Indigenous comparison across many socioeconomic and health variables. It has been notably effective in the reform of State and Territory registrations of vital events. Len Smith says that agitation on this point began around 1965 (Smith 1982: 16). According to the ABS (2000a: Table 11.6, p.162), these are the periods within which the various Australian governments put an Indigenous identifier into databases relevant to demography and to population health analysis:

- birth notification forms (1984-1996)

- death notification forms (1985-1996)

- medical certificates (cause of death) (1983-1999)

- medical certificates (cause of perinatal death) (1983-1999)

- hospital separations (1979-1997)

- maternal/perinatal collections (1982-1996)

- cancer registrations (1977-1992)

- communicable diseases notification forms $\left(1988^{-}\right)^{5}$

On at least one occasion, the reform of administrative data was stimulated by the demands of a focused inquiry with statutory powers. When the Royal Commission into Aboriginal Deaths in Custody (RCADC) began, its staff knew they could draw on the prison censuses that had begun to use an Indigenous identifier in 1982. But what data was there about police custody? The Royal Commission used its prestige and legal powers to persuade all of Australia's Commissioners of Police to allow the research staff to conduct a National Police Custody Survey in August 1988 (Commonwealth of Australia 1991: 191-2). Analysis of these data led to a conclusion that determined much of the Commission's subsequent agenda: that deaths in custody were disproportionately

${ }^{5}$ I have no information on the changes in communicable diseases notification forms since 2000 . 
Aboriginal not only because of factors within custody but also because Aborigines were much more likely than non-Aborigines to be in custody. What accounted for this higher rate of incarceration, the Commission asked? The Commission postulated the related concepts of 'self-esteem' and 'underlying issues' in order to adduce research on education, labour market status, health and other factors (using data from the 1971 to 1986 censuses) to explain Aborigines' disproportionate entry into police or prison custody.

Second, the reformed statistical archive makes some use of the organisational capacities known as 'the Indigenous sector', for example in Community Housing and Infrastructure Needs Surveys (CHINS) of 1992 and 1999 and in a current Mental Health Survey. The 1999 CHINS collected data from 707 Indigenous housing organisations and 1291 'discrete communities' (1089 of which had an identified housing organisation). 'Data ... were collected through personal interviews with key members of Indigenous housing organisations and communities who were knowledgeable about housing and infrastructure issues. Such people included community council chairpersons, administrators, coordinators, clerks, housing officers, water and essential service officers. Information regarding health services was generally collected from health clinic administrators.' (ABS 2000b: 62).

Third, there is a continuing concern to improve the methodology of data collection in remote and very remote Australian communities (Martin et al. 2004).

Fourth, we risk becoming data rich and theory poor. Our data are useful only if we have some theoretical framework in which to make sense of them. Perhaps the most developed theoretical model that we have, at the moment, is that which I mentioned in my introduction. The Productivity Commission's 2003 Report operationalises the 'strategic areas for action' in terms of thirty variables on which Indigenous and non-Indigenous can be compared (see Steering Committee for the Review of Government Service Provision [SCRGSP] 2003). The theoretical model at the centre of this strategy highlights the familial and educational conditions of Indigenous childhood that are conducive to (or destructive of) an Indigenous person's later fortunes in the labour market. It would be a useful exercise to compare this theoretical model with predecessors such as Rowley (1966) who drew on North American studies of the pathologies of institutions, and the Royal Commission's, with its focus on the material determinants of low self-esteem. That is the task for another paper. One of the questions that such a paper might address is how 'Indigenous culture' is defined as a quantifiable variable in our (more or less conscious) theoretical models, and what significance, if any, is attributed to it.

Fifth, we are producing more and more data at a time when the government is terminating the existence of at least one of the bodies - the Aboriginal and Torres Strait Islander Commission (ATSIC) - that should be the primary users of the 
data. I endorse the point, made by a number of authors in this volume, that one of the best reasons for having a rich Indigenous statistical archive is to enable the Indigenous sector to talk back to government about policy and about program effectiveness.

Sixth, in the often angry, frustrated and demoralised public discussion of Indigenous affairs policy, we now have two kinds of language for talking about Indigenous disadvantage. Here I would like to invoke the work of the Canadian philosopher Charles Taylor. In his recent book, Modern Social Imaginaries (Taylor 2004a), he says that we moderns have developed the ability to think about social life in two distinct ways, both of which are valid and useful. On the one hand, we can think about society as a series of interactions between variables. There are several papers in this monograph in which that was the idiom for thinking about society. The Productivity Commission Report is, again, a wonderful example of that way of thinking. On the other hand, we can think about society as an interaction between responsible, intentional agents, such as individual people, and organised collectives of people or organisations, including governments. Taylor says that the modern social imaginary-that is, our taken-for-granted ways of thinking about 'society' - is 'bifocal'; we use both mechanistic and agent-centred thinking. We imagine society in mechanistic terms - interactions between variables - and we imagine society humanistically - interactions between thinking, feeling agents who can be held responsible for what they do.

In contemporary Australia, both ways of thinking about society have been recently intensified. On the one hand, due to the reforms of the statistical archive, we have data with which to think about the interactions among an increasing number of variables. On the other hand, we have the language of welfare reform, with its emphasis on 'mutual responsibility' and 'Shared Responsibility Agreements' (SRAs). This language also has a horror of any 'welfare' that is 'passive' and a strong implication that Indigenous Australians may fail in their responsibilities to take up the opportunities that the public and private sector provide. In contemporary Australian public culture, the mechanistic social imaginary that is fortified by our rich statistical archive is in daily juxtaposition with the voluntaristic social imaginary that asks: are governments living up to their responsibilities to Indigenous Australians and are Indigenous Australians taking responsibility for their own advancement? 